\title{
Occlusal Caries: Biological Approach for Its Diagnosis and Management
}

\author{
ORCA Saturday Afternoon Symposium, 2015
}

\author{
Joana Christina Carvalho ${ }^{a}$ Irene Dige ${ }^{b}$ Vita Machiulskiene ${ }^{c}$ Vibeke Qvist ${ }^{d}$ \\ Azam Bakhshandeh $^{d}$ Clarissa Fatturi-Parolo ${ }^{\text {e }}$ Marisa Maltz ${ }^{\mathrm{e}}$ \\ a Faculty of Medicine and Dentistry, Catholic University of Louvain, Brussels, Belgium; ${ }^{b}$ Department of Dentistry, \\ HEALTH, Aarhus University, Aarhus, and ' Faculty of Odontology, Lithuanian University of Health Sciences, Kaunas, \\ Lithuania; ${ }^{d}$ Department of Odontology, Faculty of Health and Medical Sciences, University of Copenhagen,

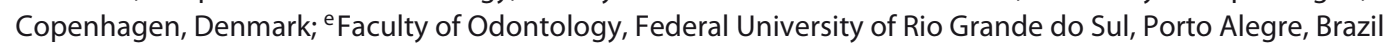

\section{Key Words}

Dental biofilms · Plaque index - Occlusal caries .

Non-cavitated caries lesions $\cdot$ Fissure sealants $\cdot$ Dental pulp

\begin{abstract}
The management of occlusal caries still remains a major challenge for researchers as well as for general practitioners. The present paper reviews and discusses the most up-todate knowledge and evidence of the biological principles guiding diagnosis, risk assessment, and management of the caries process on occlusal surfaces. In addition, it considers the whole spectrum of the caries process on occlusal surfaces, ranging from the molecular ecology of occlusal biofilms to the management of deep occlusal caries lesions. Studies using molecular methods with focus on biofilms in relation to occlusal caries should explore the relationship between the function and the structural composition of these biofilms to understand the role of occlusal biofilms in caries development. State-of-the-art measures to evaluate risk for occlusal caries lesion activity, caries incidence, and progression should include the assessment of the occlusal biofilm and the stage of tooth eruption. Careful clinical examination of non-cavitated lesions, including assessment of the lesion
\end{abstract}

activity status, remains the major tool to determine the immediate treatment need and to follow on the non-operative treatment outcome. Even medium occlusal caries lesions in the permanent dentition may be treated by non-invasive fissure sealing. By extending the criteria for non-invasive treatments, traditional restoration of occlusal surfaces can be postponed or even avoided, and the dental health in children and adolescents can be improved. Selective removal (incomplete) to soft dentin in deep carious lesions has greater success rates than stepwise excavation. Selective (complete) removal to firm dentin has a lower success rate due to increased pulp exposure.

(c) 2016 S. Karger AG, Basel

Changes in the overall pattern of dental caries in different populations and age groups have manifested themselves as a significant decline in caries prevalence since the mid-1970s [Marthaler, 2004; Bernabé and Sheiham, 2014; Lagerweij and van Loveren, 2015; WHO, 2015]. This decline has been followed by a reduction in the rate of caries progression, favoring early diagnosis and management of the caries process. Currently, the major challenge in the management of the caries process is to con-

\section{KARGER}

E-Mail karger@karger.com

www.karger.com/cre (c) 2016 S. Karger AG, Basel

0008-6568/16/0506-0527\$39.50/0
J.C. Carvalho, Associate Professor

Faculty of Medicine and Dentistry

Catholic University of Louvain

Av. Hippocrate 10, BE-1200 Brussels (Belgium)

E-Mail joana.carvalho@uclouvain.be 
trol its progression by non-operative treatments and by limiting the number of individuals in a population subjected to operative treatments.

Epidemiological studies in contemporary populations have shown the extent to which occlusal caries contributed to the caries experience of individuals in the permanent dentition. In children and adolescents, occlusal surfaces are the sites most likely to have caries experience from the beginning of tooth eruption. The tooth types with the highest caries experience are first molars followed by second molars. Concerning the groups of teeth, molars are often and premolars are seldom attacked by dental caries [Carvalho et al., 2001; Van Nieuwenhuysen et al., 2002; Batchelor and Sheiham, 2004; Carvalho, 2014]. A recent Danish study has shown that half of the caries experience in 18-year-olds is located occlusally, although the occlusal surfaces constitute less than $15 \%$ of all surfaces in the dentition [Nørrisgaard et al., 2016].

In young adults, occlusal and proximal surfaces show similar caries experience measured both clinically and/or at bite-wing radiographs. However, occlusal surfaces are more severely attacked than proximal surfaces when considering the degree of severity of the caries lesions [Mejàre et al., 2004; Van Nieuwenhuysen et al., 2004; Carvalho et al., 2015]. Therefore, the management of occlusal caries still remains a major challenge for researchers as well as for general practitioners.

In July 2015, the 62nd Congress of the European Association for Caries Research was held in Brussels, Belgium. The theme of the ORCA Saturday Afternoon Symposium was occlusal caries, which was presented in five abridged lectures. This paper is based on these lectures and discusses the most up-to-date knowledge and evidence of the biological principles guiding diagnosis, risk assessment, and management of the caries process on occlusal surfaces. In doing so, it considers the whole spectrum of the caries process on occlusal surfaces, ranging from the molecular ecology of biofilms on occlusal surfaces to the management of deep occlusal caries lesions.

\section{Molecular Ecology of Biofilms on Occlusal Surfaces}

Diagnosis, risk assessment, and optimal management of occlusal caries lesions require an understanding of the factors causing the caries lesion to develop and progress. It is well established that the biofilm on occlusal surfaces is the key etiological factor in the development of occlusal caries. The macromorphology of the occlusal surface favors the adherence of bacteria because of its groove-fossa- system together with a relatively long eruption period with reduced mechanical oral function [Carvalho et al., 1992]. These mechanically protected sites may facilitate accumulation and maturation of biofilms that can potentially develop into cariogenic biofilms if an imbalance of metabolic activity occurs due to changes in the local environmental conditions [Marsh, 1994; Takahashi and Nyvad, 2008]. Therefore, for many years numerous research studies have aimed to investigate the bacterial composition and structure of dental biofilms.

There are a variety of methods available for studies of dental biofilms. An overview of molecular microbiological and metabolomic techniques and how they have been used in caries research was given in a recent review by Nyvad et al. [2013]. For studies of oral microbial communities, the methods can be divided into either descriptive or functional approaches, providing information about microbial composition and function of the microbial community, respectively. Molecular techniques have allowed the identification of more than 600 oral bacterial species, many of which have not yet been cultured [Aas et al., 2005; Dewhirst et al., 2010; Peterson et al., 2013], and Keijser et al. [2008] have estimated that 19,000 phylotypes contribute to the ultimate oral species diversity. Detailed characterization of the oral microbiome in patients with or without caries has thus been performed using these newer molecular techniques, most of which are based on $16 \mathrm{~S}$ rRNA sequencing data [Aas et al., 2008; Peterson et al., 2013]. The distinction between the microbiota from caries-free individuals and caries-active individuals seems to be related to a shift in abundance of groups of bacterial species during the caries process. Thus, several studies suggest that the bacterial composition is more diverse in the caries-free individuals compared with individuals presenting caries [Li et al., 2007; Aas et al., 2008; Jiang et al., 2011; Peterson et al., 2013]. However, there are large variations in the distribution of prevalent species between studies. These variations could be ascribes to inter-individual variation, different sampling methods, and even differences in categorizing patients into the two groups.

Many studies applying molecular techniques for studies of the bacterial composition of dental biofilms do not differentiate between biofilms deriving from occlusal surfaces or other surfaces such as smooth and approximal surfaces. In fact, most molecular studies are based on saliva samples or pooled plaque samples. A study by SimónSoro et al. [2013] aimed to determine the bacterial diversity of different oral microniches and to assess whether saliva and plaque samples are representative of oral microbial composition. Of particular interest, the authors found 
that saliva samples, especially non-stimulated saliva, were not representative of supra- and subgingival plaque but also that differences in the microbial composition were observed between buccal and lingual surfaces. Therefore, it could be speculated that a similar difference exists between occlusal surfaces and other tooth surfaces. This supports the view that a site-specific sampling method is of great importance to achieve a better understanding of the role of bacterial composition in relation to both site and stage of caries lesion progression [Nyvad et al., 2013].

Site-specific sampling of occlusal caries lesions has already been performed and analyzed by the newer molecular techniques, but the studies have been limited to only include more advanced stages of caries lesions involving the dentin [Munson et al., 2004; Aas et al., 2008; Arif et al., 2008; Mantzourani et al., 2009; Lima et al., 2011]. These studies have shown that numerous bacterial species are present, but in particular Lactobacillus spp., Bifidobacterium spp., Atopobium spp., Propionibacterium spp., and Veillonella spp. were regularly isolated from occlusal dentin lesions. To our knowledge, detailed sitespecific information about the composition of biofilm in earlier stages of occlusal caries progression without involvement of the dentin is still limited to results based on traditionally culture-dependent techniques. Such studies of samples from natural fissures have demonstrated Actinomyces spp., Streptococcus spp., and Lactobacillus spp. to be prevalent [Loesche et al., 1984; Meiers and Schachtele, 1984]. However, these studies have also demonstrated that narrow fissures are particular difficult to sample due to the inaccessible morphology of the fissures [Meiers and Schachtele, 1984]. To overcome this problem, researchers have used in situ models or artificial fissure models in the past [Löe et al., 1973; Theilade et al., 1976].

Whether sampling is possible or not, the natural structure of the biofilms will always be destroyed, thus loosing information about the architecture of the biofilm. Previously, transmission electron microscopy was the preferred method for studying biofilm organization and the structure of occlusal biofilms [Theilade et al., 1976; Ekstrand and Bjørndal, 1997]. These studies elegantly demonstrated differences in the biofilm structure depending on the location within the groove-fossa-system of occlusal surfaces. However, it was not until recently that the spatial distribution of different bacterial taxa in various stages of occlusal caries was demonstrated using a molecular methodology based on fluorescence in situ hybridization (FISH) [Dige et al., 2014]. This method was originally introduced by Amann et al. [1990] and later used to describe colonization patterns of both in situ

Occlusal Caries: Biological Approach for

Its Diagnosis and Management grown dental biofilms [Al-Ahmad et al., 2009; Dige et al., 2009] and in vivo supra- and subgingival biofilms [Zijnge et al., 2010]. The FISH methodology used to study occlusal biofilm was based on demineralized and reembedded hard dental tissue slices prepared from extracted teeth and was shown to represent a valuable supplement to previous methods for the study of microbial ecology in caries because it allowed analysis of the three-dimensional distribution of abundant species and genera in dental caries lesions in vivo [Dige et al., 2014]. The study showed the presence of ecological niches in occlusal caries with distinct different bacterial compositions. For example, a diverse bacterial composition was demonstrated above the entrance of fissures showing similar features to supragingival biofilms (examples in fig. 1a). In contrast, the biofilm within fissures was less diverse and seemed less metabolically active - a finding that is in accordance with previous studies [Theilade et al., 1976; Ekstrand and Bjørndal, 1997]. The presence of mineralization in shallow fissures has been speculated to influence the ecological environment in those areas [Galil and Gwinnett, 1975; Theilade et al., 1976; Ekstrand and Bjørndal, 1997]. Reduced availability of nutrients from saliva and food may be another reason for a less metabolic active biofilm within the fissure proper compared with the outer areas of the biofilm at the entrance of the fissure. When cavitation of enamel was observed, aciduric bacteria such as Streptococcus mutans, Lactobacillus spp., and Bifidobacterium spp. were observed (examples in fig. 1b, c). The previous finding of bacteria in dentin only in stages with manifest cavity formation [Edwardsson, 1974; Hoshino, 1985; Thylstrup and Qvist, 1987] was verified in the FISH study by the presence of Lactobacillus spp. and Bifidobacterium spp. within the dentinal tubules.

While FISH methods can give information about the three-dimensional arrangement of bacteria within intact biofilms in caries lesions, it has shortcomings like any other method. The most obvious disadvantage is that the caries-associated biofilm can only be evaluated at the time of tooth extraction so that population dynamic as well as intervention studies cannot be analyzed. Other methodological considerations have previously been discussed [Dige et al., 2014]. However, in future it could be interesting to investigate further the relationship between clinically diagnosed lesion activity and the microbial ecology of the dentin that presents radiographic signs of demineralization. Pilot studies of excavated demineralized dentin using the FISH technique with confocal microscopy have confirmed the presence of bacteria within dentinal tubules with characteristic coalescence and breakdown of 

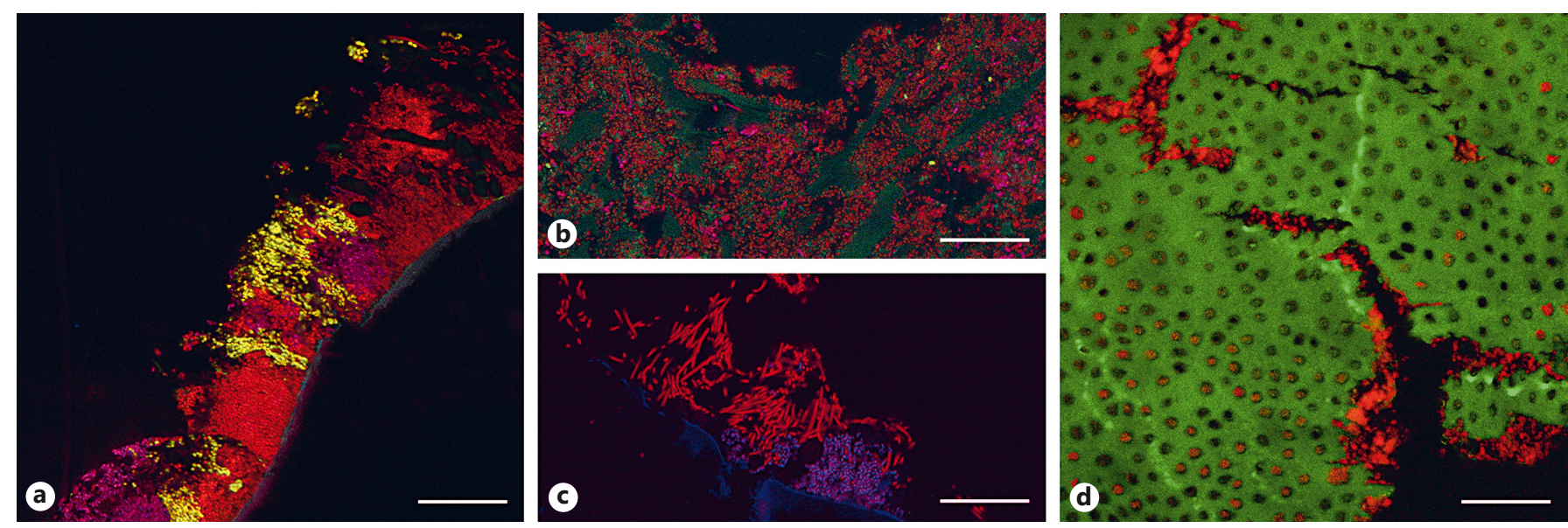

Fig. 1. Confocal images after FISH of in vivo biofilms from teeth with occlusal caries. a Biofilm at the entrance of occlusal fissures from an extracted tooth; yellow-green, purple-blue and red represent Streptococcus spp., Actinomyces spp., and the remaining bacteria, respectively. b, c Biofilm from cavitated caries lesion; green, purple, and red represent Streptococcus spp., Lactobacillus spp., and the remaining bacteria, respectively (b), and purple and red represent Bifidobacterium spp. and the remaining bacteria, respectively (c). d Excavated demineralized dentin (green autofluorescence) from occlusal caries lesion with the presence of bacteria (red) within the dentinal tubules. a-c Previously unpublished images from the study by Dige et al. [2014]. Scale bars: $25 \mu \mathrm{m}$. adjacent dentinal tubules filled with bacteria-forming liquefaction foci (example in fig. 1d).

Although many molecular methods are available today and have provided valuable information about biofilm composition and structure, only few studies have focused on occlusal surfaces, and in particular the early stages of caries have not been examined in detail. In future, it would be interesting to combine the findings from the descriptive molecular methods with new approaches determining biological function. The functions of oral biofilms are still poorly understood and rely on the measurement of metabolic activity, which is difficult to analyze [Takahashi, 2015]. However, recent advances in metabolomic technology make it possible to investigate in detail the relationship between metabolic activity and biofilm-associated diseases [Takahashi, 2015]. This would contribute to a better understanding of the role of (cariogenic) biofilms in occlusal caries development, with possible contributions to caries risk assessment and monitoring of caries activity at individual and tooth surface levels [Nyvad et al., 2013].

\section{Risk Assessment for Occlusal Caries Lesion Activity, Incidence and Progression}

In parallel with research on (cariogenic) biofilms by molecular methods, clinical studies investigating the occurrence and distribution of the occlusal biofilm are of interest for assessing the risk of occlusal caries incidence and progression, supporting treatment decisions, and managing the caries process in daily practice.

Few indices are available in the literature for research on occlusal biofilm [Carvalho et al., 1989; Addy et al., 1998; Levinkind et al., 1999; Nourallah and Splieth, 2004]. The Visible Occlusal Plaque Index (VOPI) was developed to assess the occurrence and distribution of occlusal biofilm in relation to caries [Carvalho et al., 1989], while other indices were developed to measure the occurrence of occlusal biofilm before and after the performance of oral hygiene procedures by mechanical or chemical means [Addy et al., 1998; Levinkind et al., 1999; Nourallah and Splieth, 2004].

Longitudinal studies investigating the occurrence and distribution of the occlusal biofilm during tooth eruption in relation to caries by means of the VOPI showed that erupting occlusal surfaces favored the accumulation of thick and heavy plaque due to their limited mechanical oral function and difficulties associated with toothbrushing. Simultaneously, a higher incidence of active lesions was observed in erupting occlusal surfaces in contrast with fully erupted surfaces that mainly presented no or thin plaque scores and inactive lesions [Carvalho et al., 1991, 1992, $2009,2014]$. These findings were further confirmed by other clinical trials on occlusal caries [Ekstrand et al., 2000; Maltz et al., 2003; Farzão, 2011; Vermaire et al., 2014].

Modern approaches of caries management include risk assessment and prediction as these tools are considered essential for treatment decisions in daily practice 
[Twetman and Fontana, 2009; Fontana et al., 2011]. The underlying assumption in caries risk assessment is that in some individuals or tooth surfaces/sites the caries process is more likely to develop than others. Risk factors are defined as environmental, behavioral, or biological factors confirmed by a temporal sequence, usually in longitudinal studies, which, if present, directly increase the probability of a disease occurring and, if absent or removed, reduce the probability. Risk factors are part of the causal chain [Beck, 1998]. According to this definition, occlusal biofilm is a risk factor for the occurrence of occlusal caries [Carvalho, 2014]. However, the question of interest is how accurately can we identify individuals or tooth surfaces/sites at risk by assessing risk factors?

Limited evidence on the validity of available methods used for risk assessments has been reported in the literature [Tellez et al., 2013; Twetman et al., 2013; Mejàre et al., 2014; Senneby et al., 2015; Divaris, 2016]. The ability of multivariable or single determinant models to predict caries in children and adolescents was recently investigated in a systematic review [Mejàre et al., 2014]. The following non-biological and biological determinants were included in these models: sociodemographic, age, sex, mother's education, behavior, oral hygiene, dental plaque, dietary habits, baseline caries prevalence, salivary flow, salivary buffer, salivary microbial tests, fissure morphology, cariogram, incipient lesions, enamel hypoplasia, and posteruptive age. The accuracy was better for multivariable models than for single predictors. Among the single predictors, baseline caries experience had from good to limited accuracy in preschool children and adolescents, respectively. The highest risk period for caries incidence in permanent teeth was the first 3-4 posteruptive years. However, longitudinal studies carried out from the very beginning of tooth eruption showed that the period of tooth eruption was of highest risk [Carvalho, 2014]. While risk predictors are useful to identify who or which site/surface is at risk, they are not useful in identifying likely interventions [Beck, 1998].

Caries activity is determined by lesion characteristics which indicate whether or not there is ongoing net mineral loss [Thylstrup et al., 1994]. Thus, caries lesions within the dentition of individuals may be designated as active or inactive, and individuals may be categorized as caries active or caries inactive. The main concern about cariesactive patients (those with at least one active lesion) is that the caries process is likely to develop unless effective measures are implemented to interfere with its progression. On the other hand, in caries-inactive patients (those with only inactive lesions) the caries process has evolved to a
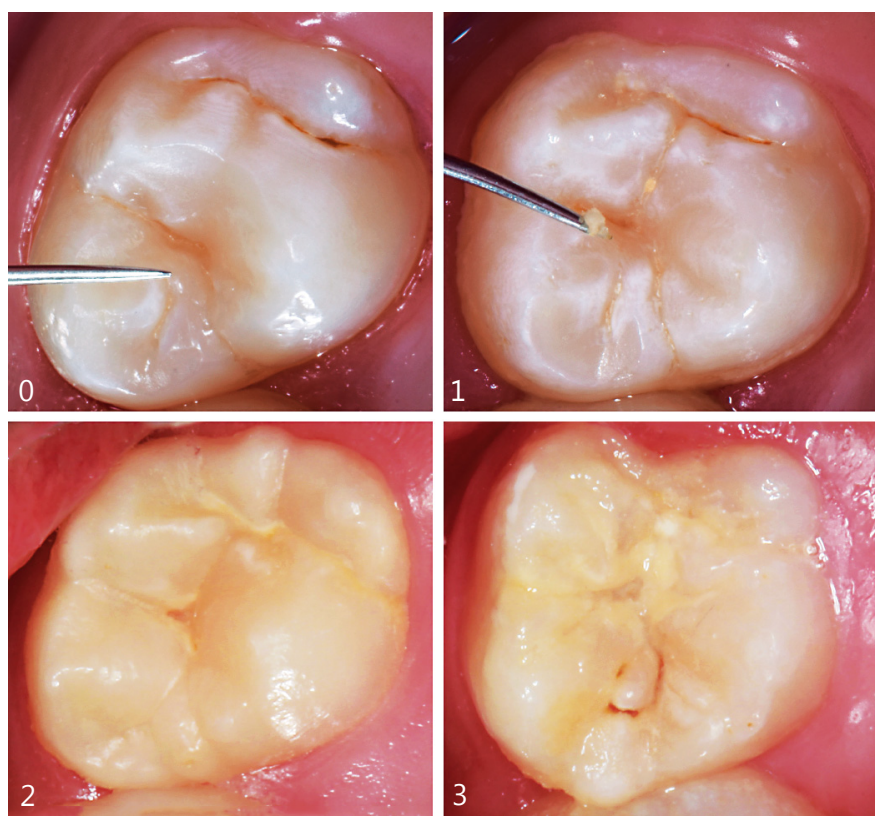

Fig. 2. Clinical pictures illustrating the VOPI scores: $0=$ no visible plaque identified but carefully running a dental probe on the groove-fossa-system; 1 = thin plaque identified by carefully running a dental probe on the groove-fossa-system; 2 = thick plaque identifiable with the naked eye; 3 = heavy plaque covering partially or totally the occlusal surface.

certain extent, but its further development is unlikely unless changes in the oral environment take place. The latter also applies to patients with a history of no caries experience for extended periods of time.

Nyvad et al. [2003] validated caries lesion activity according to surface characteristics in terms of reflection and texture - chalky and rough non-cavitated lesions generally covered with plaque being active and smooth, shiny, and hard non-cavitated lesions being inactive [Nyvad et al., 1999]. Overall, these surface characteristics match well with the presence of active or inactive noncavitated lesions. However, on occlusal surfaces the distinction between active non-cavitated lesions and active non-cavitated lesions in the process of inactivation may be challenging.

Recently, the VOPI was examined for its ability to estimate caries lesion activity status on occlusal surfaces. Figure 2 illustrates the four possible scores of the VOPI as follows: $0=$ no visible plaque identified when carefully running a dental probe on the groove-fossa-system; 1 = thin plaque: hardly detectable plaque which is restricted to the groove-fossa-system and identified by carefully 
Fig. 3. Dental caries profile of the occlusal surfaces of the permanent molars of 5- to 6-year-old Lithuanian children (mean values with SD). A total of $39 \%$ of the occlusal surfaces in this group were affected by caries.

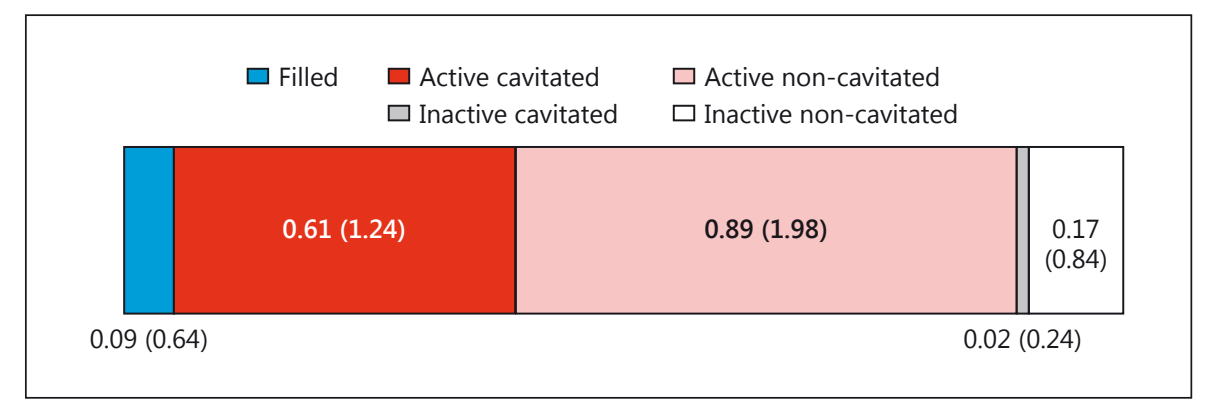

running a dental probe on the groove-fossa-system; $2=$ thick plaque: easily detectable plaque on the groove-fossa-system identifiable with the naked eye; and $3=$ heavy plaque: occlusal surfaces partially or totally covered with heavy plaque accumulation identifiable with the naked eye [Carvalho et al., 1989]. The underlying principle of examining this index for its ability to estimate caries lesion activity status was that different plaque scores were likely to be related to particular caries lesion activity status [Carvalho et al., 1989, 1991, 1992, 2014].

The likelihood that the scores of the VOPI were associated with caries lesion activity status was examined in Brazilian adolescents $(n=618)$ enrolled in a comprehensive controlled clinical trial designed to control caries incidence and progression (Brazilian register number 1.096.882). The VOPI, measured on 4,506 molars, was included in a model with multiple non-biological and biological determinants and analyzed by means of a general linear model, fitted using generalized estimation equations. The analyses showed that different scores of the VOPI were the most influential determinants for occlusal surfaces status. Sound occlusal surfaces $(\mathrm{p}<0.001)$ and occlusal surfaces with inactive non-cavitated lesions ( $\mathrm{p}=0.019)$ were significantly associated with no plaque or thin plaque (scores 0 and 1 ). In contrast, occlusal surfaces with active non-cavitated lesions $(\mathrm{p}<0.001)$ and cavitated lesions $(\mathrm{p}<0.001)$ were associated with thick or heavy plaque (scores 2 and 3, respectively). Age (13-15 years), stage of eruption (fully erupted molars), and type of molars (first molars) were significant determinants for inactive lesions ( $\mathrm{p} \leq 0.012$ ). Fully erupted first molars limit the accumulation of occlusal biofilm by their mechanical oral function, offer better conditions for toothbrushing, and have been in the oral environment for a long period of time allowing inactivation of lesions. In contrast, second molars were significant determinants for sound occlusal surfaces $(\mathrm{p}<0.001)$, which is consistent with the teeth having been exposed to the oral environ- ment for a shorter period of time and less likely to develop caries lesions provided regular removal of the dental biofilm was performed. On the other hand, second molars were also significant determinants for active occlusal lesions $(\mathrm{p}<0.001)$ as partially erupted second molars favored accumulation of the occlusal biofilm with cariogenic potential and were likely to develop caries lesions if the dental biofilm was not regularly and sufficiently removed. The use of the VOPI is recommended as an additional clinical tool to estimate caries lesion activity along with the clinical characteristics of the lesions and to support treatment decisions in daily practice.

In this context, the implementation of measures interfering with surface net mineral loss should result in lesions being maintained at subclinical levels. Lack of implementation of these measures might have as consequence many lesions progressing to clinical level - in the early stages as non-cavitated lesions.

\section{Challenges in Diagnosing and Managing Non-Cavitated Occlusal Lesions}

It is well known that including non-cavitated lesions in the measurements of caries prevalence considerably changes the caries profile in populations. As an example, the data from the recent national survey in Lithuania showed that about $50 \%$ of the newly erupted first permanent molars presented non-cavitated lesions, and the majority of those lesions were active. The dental caries profile of the occlusal surfaces of the permanent molars of 5- to 6-year-old Lithuanian children is illustrated in figure 3 [Razmiene, 2013]. This is a 'call for attention', an indicator of a significant risk of disease progression. If the non-cavitated lesions had been omitted, a very important message about the disease prevalence and severity in this population would have been missing. 
The proportion of non-cavitated occlusal lesions can constitute up to two thirds of all occlusal lesions recorded. The differences in the proportions are even more prominent in populations with low caries prevalence as most of the lesions found would still be at the non-cavitated stage of development [Ismail, 2004].

The overall reliability of recording dental caries at the non-cavitated threshold of diagnosis is generally reported as good or excellent. There is a trend to observe somewhat lower levels of reliability in populations with high caries prevalence - possibly because there are fewer sound surfaces and, thus, more chances of recording errors. When examiners have been extensively trained and calibrated, reliability of caries lesion detection at the non-cavitated level of diagnosis is not affected to a significant degree [Fyffe et al., 2000]. Intra-examiner reliability is often higher than inter-examiner reliability [Machiulskiene et al., 2009; Carvalho and Mestrinho, 2014].

As observed in the series of clinical testings of the Nyvad criteria, the reliability of clinical caries lesion diagnosis in the occlusal surfaces was comparable with that in the approximal surfaces. While the total percentage of disagreements was slightly higher for the occlusal than for approximal surfaces, generally, there was a tendency to make more errors for non-cavitated lesions on approximal than on occlusal surfaces. Thus, the number of errors for approximal surfaces increased 4 times, while in the occlusal surfaces it increased twice when the clinical caries diagnostic threshold was changed from the cavitated to the non-cavitated level [Machiulskiene, 1999].

The diagnostic process for the occlusal surfaces can be impaired by various factors: the presence of dental plaque, non-standardized examination process (poor light, presence of saliva, difficult access, etc.), and the presence of other enamel defects on the surface (dental fluorosis, hypoplasia, $\mathrm{MIH}$, etc.). In order to improve the diagnostic process, the most commonly used clinical caries scoring systems emphasize the need to perform examinations on clean dental surfaces in standardized clinical settings [Nyvad et al., 1999; Topping and Pitts, 2009]. However, a thorough clinical examination may be performed even under field conditions provided that the equipment includes all necessary armamentarium [Carvalho and Mestrinho, 2014]. Concerning the differential aspects of non-cavitated caries lesions and other defects of non-caries origin, lesion location is the major decisive factor for the diagnosis of dental caries, along with other clinical characteristics such as distribution in the dentition, lesion shape, and morphology [Nyvad et al., 2009].

Occlusal Caries: Biological Approach for

Its Diagnosis and Management
Generally, the diagnosis of non-cavitated lesions is very important in the treatment planning process. Looking from the patients' perspective, the number of lesions detected during examination is of less concern than the treatment decisions based on what has been recorded. The consequences of such decisions are closely related to the expected oral health benefits as well as to the treatment costs. However, caries diagnostic decisions as well as decisions about when to intervene vary considerably among dental practitioners. A tendency to overestimate the presence and depth of caries lesions as well as to treat enamel lesions invasively has been reported [Gordan et al., 2010; Al-Khatrash et al., 2011], particularly when several diagnostic tools were employed. Along with slight or no improvement in the percentage of correctly diagnosed sites, a drastic effect on the selection of treatment options, most commonly invasive interventions, was observed [Pereira et al., 2009; Baelum et al., 2012]. No doubt, a careful clinical examination of the occlusal surfaces remains the major tool in the decision-making process, while other caries detection methods (such as radiography or fluorescence-based methods) may not be sufficiently sensitive for identifying early stages of caries lesion development and are more suitable for detecting advanced lesions [Gimenez et al., 2013; Schwendicke et al., 2015c]. Thus, when the relative diagnostic yields of the clinical and the radiographic examination were compared at the non-cavitated level of caries diagnosis, the radiographs added only $2 \%$ to the total number of caries lesions on the occlusal surfaces, while the clinical examination alone revealed about $40 \%$ more lesions compared with the radiographs [Machiulskiene et al., 1999]. Furthermore, as demonstrated for occlusal lesions by Bertella et al. [2013], no association was observed between the presence of enamel breakdown and the presence or depth of the radiolucent image.

Assessing the activity status of caries lesions is an essential part of caries diagnosis as active lesions require active management while arrested lesions do not need any intervention [Nyvad and Fejerskov, 1997].The characteristics of the lesion activity based on the surface features were originally described by Thylstrup et al. [1994] and later on designed into a criteria system and validated during randomized clinical trials [Nyvad et al., 1999, 2003]. Lesion discrimination with respect to the activity status allows continuous monitoring of the lesions and improves the evaluation of the applied treatment. The survival analysis of the caries lesion transitions over time has shown that the occlusal surfaces, particularly during the eruption period, seem to be at a significantly higher 
risk of developing into more severe stages than any other surface types [Baelum et al., 2003; Fereira-Zandona et al., 2012]. However, the occlusal caries lesions seem to respond well to non-operative treatments [Carvalho et al., 1991, 1992]. The lesion progression slows down in the surfaces that have been regularly exposed to supervised toothbrushing with fluoride toothpaste [Baelum et al., 2003]. Moreover, the lesion regression rates in the occlusal surfaces subjected to non-operative treatment were found to be considerably higher than in other types of surfaces [Baelum et al., 2003; Maltz et al., 2003]. Clinical studies focusing on dental plaque removal and topical fluoride application on the occlusal surfaces of erupting permanent molars found significant differences in the numbers of progressed lesions and sealed and filled surfaces between the test and control groups over time [Carvalho et al., 1992; Ekstrand et al., 2000]. Interestingly, the long-term effect of non-operative treatment was observed up to 18 years after the implementation of the preventive programs: the caries experience as well as the dental plaque levels were lower in those individuals who had participated in the preventive program than in those who had not [Kuzmina and Ekstrand, 2015].

The major challenges for caries control on occlusal surfaces are related not to the detection of non-cavitated lesions per se but rather to the subsequent treatment strategies. In order to bring most benefit to patients, the main task of today is to control caries progression by non-operative means where possible. Therefore, evaluation of every dental surface should be based first of all on the clinical criteria that allow defining the immediate treatment needs in accordance with the activity status of the detected lesions as well as following up the treatment outcomes.

The collaboration between dental professionals and individual patients or populations should lead to a scenario in which active non-cavitated lesions become inactive. However, for some individuals or group of individuals the caries process may develop to an extent to which operative treatment is required. Recent advances in operative treatments of occlusal lesions related to their activity and severity are presented and discussed in the following sections.

\section{Management of Small and Medium Occlusal Caries Lesions}

Occlusal surfaces are continuously treated for caries and its sequels, resulting in very few sound surfaces in individuals during adulthood. Also, with the passage of time an increasing number of occlusal surfaces are registered as missing due to extractions [Kongstad et al., 2013]. In other words, dental caries and its traditional treatment have an adverse effect on the dental health of the population [Qvist, 2015].

After the introduction of the acid etch technique in the late 1960s, fissure sealants have been used for preventive measures with a high success rate [Ahovuo-Saloranta et al., 2013]. The caries reduction in the young permanent dentition is highly significant, even after several years [Simonsen, 2002; Beauchamp et al., 2008]. Moreover, sealed permanent molar teeth will need restorative treatment less frequently compared with unsealed molars, there will be an increased time between tooth eruption and restoration of sealed teeth, and the restorations will be less extensive, resulting in prolonged longevity [Beauchamp et al., 2008; Schwendicke et al., 2015b].

Promising results have also been obtained for the therapeutic sealing of active non-cavitated enamel lesions in permanent teeth and the sealing in of caries enamel and dentin [Simonsen, 2002; Griffin et al., 2008]. Studies have shown a reduced frequency of caries progression for up to 5 years and that a tight sealing decreases the number of viable bacteria in the lesions [Oong et al., 2008]. Sealing the enamel surface may even reduce the amount of viable bacteria in dentin caries lesions [Handelman et al., 1976; Jensen and Handelman, 1980]. A major reduction in viable microorganisms occurred during the first 2 weeks after sealing, and after 1 year, there was a 100-fold decrease in the number of cultivable microorganisms [Handelman et al., 1976]. The same group reported that caries progression was restricted to less than $50 \%$ of the lesions and that almost half of the lesions showed a decreased depth during 1-4 years of follow-up, indicating that remineralization of manifest dentin caries lesions is possible in teeth with vital pulps. Additionally, a study by Mertz-Fairhurst et al. [1998] showed that occlusal dentin caries lesions could be inactivated for up to 10 years without the removal of caries dentin tissue by superficial resin restorations. The radiographic basis for the positive conclusions by Handelman et al. [1976] and Mertz-Fairhurst et al. [1998] was sparsely illustrated in the papers, but the findings have subsequently been supported by Bakhshandeh et al. [2012], demonstrating that manifest dentin lesions can be arrested by resin fissure sealing in adults provided that the sealing is intact and tight [Bakhshandeh et al., 2012]. Except for these and a few other studies, the present knowledge of sealing dentin caries lesions is limited.

In Denmark and other European countries, the overall indication for using fissure sealants in the young perma- 


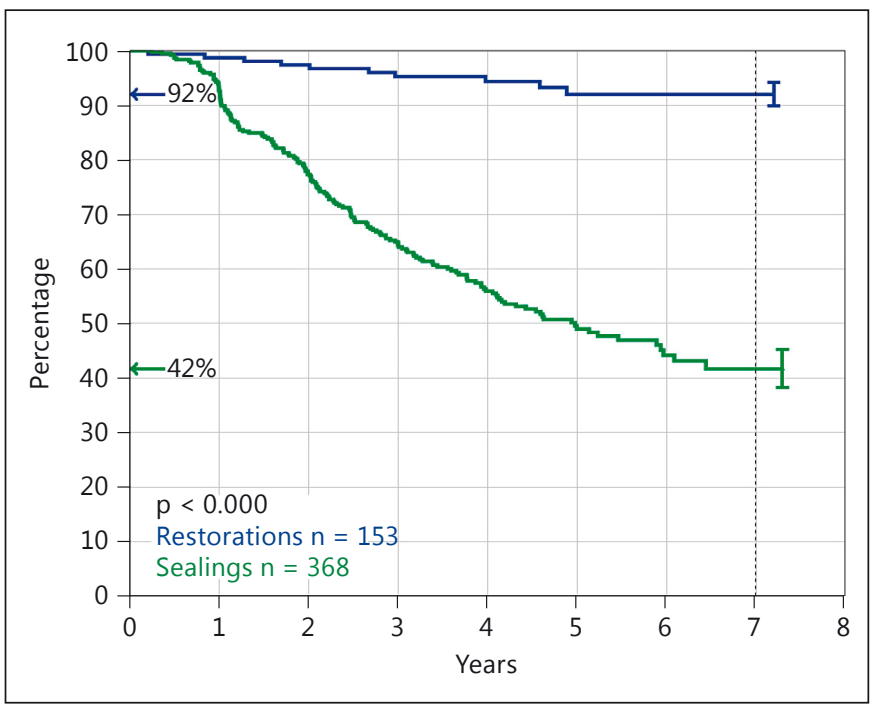

Fig. 4. Cumulative survival distribution of 153 composite resin restorations and 368 resin fissure sealants in molar teeth with manifest enamel and dentin caries lesions in Danish children and adolescents.

nent dentition has been as a preventive treatment in the case of deep fissures or a general caries risk [Welbury et al., 2004; Kervanto-Seppala et al., 2009]. Sealing is also used for the therapeutic treatment of active occlusal enamel caries lesions in the young permanent dentition, while the current strategy for active occlusal dentin caries lesions is invasive restorative treatment. However, sealants are seldom used in adults [Gore, 2010], and there has been a tendency to treat even enamel caries lesions with invasive therapy [Espelid et al., 2001; Fellows et al., 2014; Kopperud et al., 2016].

It is still an open question whether fissure sealing of caries lesions is an alternative treatment option for occlusal caries lesions in dentin assessed to be in need of restorative treatment. What we need is evidence-based knowledge from randomized, controlled clinical studies of the possibilities for inactivating occlusal caries progression without invasive intervention. The SEAL-DK study from Denmark was designed to answer this question. It was initiated in 2006 in cooperation with the Danish Public Dental Health Service as an RCT study on fissure sealing versus restorative treatment of occlusal caries lesions in permanent teeth in the young permanent dentition. It is important to emphasize that all 521 caries lesions included in the study were assessed, clinically and/or radiographically, to be in need of restorative treatment according to the current Danish treatment guidelines. Randomization was performed in $2 / 3$ of the lesions in the sealing group and only $1 / 3$ in the restoration group because we already had sufficient knowledge of class I restorations [Hickel and Manhart, 2001; Qvist, 2015]. A total of 368 resin fissure sealings in 7 marketed brands and 153 composite resin restorations in 8 brands were performed by 68 dentists. The cumulative survival analyses of longevity of the sealants and restorations from SEAL-DK are shown in figure 4. As expected, the curves illustrate the superior longevity of restorations compared with sealants. After a 7-year observation period, the success rate was $92 \%$ for the restorations and $42 \%$ for the resin sealings, with an annual failure rate of $1.1 \%$ for the restorations and $8.3 \%$ for the sealings. Although all lesions were assessed to be in need of restorative treatment at baseline, more than half of the sealed lesions were still not restored after the first 7 years, and retreatments such as repair and replacement comprised half of the registered failures. The survival rates from SEAL-DK supported the results from previous studies which indicated a failure rate of $5-10 \%$ for resin fissure sealants performed on sound or initial enamel lesions and a failure rate of $1-2 \%$ for class I resin restorations [Hickel and Manhart, 2001; Simonsen, 2002; Beauchamp et al., 2008; Griffin et al., 2008; Ahovuo-Saloranta et al., 2013; Qvist, 2015; Schwendicke et al., 2015b].

Previous studies have shown that the longevity of fissure sealants can be influenced by factors such as the patient's caries risk, the status of occlusal surface (sound/ demineralized/cavity formation), the tooth type, and the fissure sealant (brand, procedure) [Poulsen et al., 2006; Beauchamp et al., 2008; Griffin et al., 2008; Bakhshandeh et al., 2012; Ahovuo-Saloranta et al., 2013]. The retention rate of resin fissure sealants is lowest and the need for retreatments is highest in patients with moderate/high caries risk at baseline, on demineralized or cavitated tooth surfaces, and in the more posterior teeth. In order to verify the influence of these and other clinical relevant factors on the longevity of sealed and probably also restored lesions in SEAL-DK, multivariate analyses are planned to be performed.

The 7-year results from SEAL-DK have shown that the criteria for non-invasive sealing of occlusal surfaces can be extended to include small and medium occlusal caries lesions in young permanent dentition. Thus, the first placement of a traditional restoration on occlusal surfaces can be postponed for several years or even avoided. By doing so dental health in children and adolescents will be improved. 


\section{Management of Deep Occlusal Caries Lesions}

As previously highlighted, the inactivation of occlusal caries lesions may occur at different stages of the disease process. However, in cavitated lesions where the biofilm control inside the cavity is not possible, as in deep carious lesions, an operative treatment is necessary in order to stop lesion progression. Nevertheless, infected dentin tubules are frequently found after conventional caries removal to hard dentin [Banerjee et al., 2002; Shovelton, 1968; Macgregor et al., 1956]. Therefore, leaving bacteria during caries removal may be inevitable.

In the management of deep caries lesions (those with radiolucent image in more than half of the dentin thickness) an important question arises: how clean should a carious lesion be before the placement of a restoration? In deep caries lesions the non-selective removal of carious tissue to hard dentin (NSRHD; leaving only hard dentin) or the selective removal to firm dentin (SRFD; leaving leathery or firm dentin) could lead to pulp exposure [Magnusson and Sundell, 1977], consequently having a bad prognosis for pulp vitality. In order to prevent this, a caries removal in two steps - stepwise excavation (SW) treatment - has been proposed [Bjørndal et al., 1997]. In $\mathrm{SW}$, the carious dentin is incompletely removed at the bottom of the cavity floor and a temporary filling is placed. This provides remineralization and the development of tertiary dentin within the pulp chamber. In a second visit some months later, a reentry procedure is performed. At this time the dentin is usually harder and drier with characteristics of an inactive lesion [Maltz et al., 2002], and complete removal of all remaining carious tissue is performed. The SW treatment is an NSRHD or SRFD performed in two steps.

The covering of the innermost layer of carious dentin with a protective lining material for remineralization induction in the first step of the SW treatment has been discussed. The modification of the dentin aspect after SW reopening raises the question whether the arrest of the progression of the lesion is related to the sealing effect or to the sealing material chosen. Corralo and Maltz [2013] showed that, after partial caries removal and a sealing period, regardless of the liner used (calcium hydroxide, glass ionomer cement, or wax), an organized dentin was observed with total or partial obliteration of dentinal tubules. All groups showed significant bacterial reduction after the sealing period. These findings indicate that the removal of superficial parts of the necrotic and demineralized dentin and cavity sealing promotes dentin caries inactivation, irrespective of the use of a liner. Other stud- ies in primary teeth corroborate these findings [Casagrande et al., 2010; Franzon et al., 2007]. A meta-analysis about lining materials concluded that strong recommendations for using cavity liners are unsubstantiated, but firm evidence for omitting lining is also unavailable [Schwendicke et al., 2015a].

The remarkable reduction of dentin infection was also observed after selective removal to soft dentin (SRSD) and sealing (for 6 months) in comparison with NSRHD immediately after dentin caries removal (conventional treatment) [Maltz et al., 2012b]. Significantly less anaerobic bacteria, aerobic bacteria, and mutans streptococci growth was observed after SRSD compared with NSRHD. Sealing of carious dentin results in lower levels of infection compared with traditional dentin caries removal.

Although we know that SRSD and sealing (a) turns the caries lesion into one with characteristics of an inactive lesion [Maltz et al., 2002; Pinto et al., 2006], and (b) shows a decreased number of dentin infections compared with conventional caries removal treatment [Maltz et al., 2012b], many dentists still prefer SW in the treatment of deep caries lesions or SRFD/NSRHD [Weber et al., 2011].

A recent multicenter RCT [Bjørndal et al., 2010] compared SW with direct complete excavation and evaluated the pulp survival rate of teeth with exposed pulp treated with direct pulp capping or partial pulpotomy. Teeth treated with direct complete excavation presented a significantly inferior survival rate (62.4\%) compared with SW (74\%) after a 1-year follow-up period. A higher number of pulp exposures was observed after complete excavation compared with SW. The survival rate of the exposed pulp treated with direct pulp capping $(31.8 \%)$ and with partial pulpotomy (34.5\%) was very low.

Although SW treatment has shown superior results compared with NSRHD or SRFD for deep carious lesion, some limitations could be pointed out in relation to SW treatment [Maltz et al., 2012a, 2013]: (a) it requires two sessions for treatment execution, (b) it results in additional costs, time, and discomfort to the patient, (c) it increases the probability of pulp exposure during the reentry step, (d) it increases the rate of fracture or loss of temporary filling, and (e) it introduces a risk of no return of the patient for the second visit.

Due to the disadvantages of SW and the existing evidence (microbiological, ultrastructural, clinical, and radiographic), there is a concern about the necessity for cavity reopening for SRFD as is done in SW treatment.

Permanent teeth with deep caries lesions, positive response to cold test, no signs of periapical lesions, no exposed pulp, and absence of spontaneous pain should re- 
ceive non-pulp-invasive treatment. To treat this type of lesion 3 treatment options are presented here: SRFD, SW, and SRSD. The advantages and limitations of each one are discussed below:

Selective Removal to Firm Dentin. Pulp exposure is expected to occur when SRFD is performed in deep carious lesions. The conventional treatment for pulp exposure is direct pulp capping. A survival rate of $81.8 \%$ has been found for short follow-up periods ( 3 months) [Matsuo et al., 1996], decreasing to around 30\% after 1 and 3 years of follow-up [Bjørndal et al., 2010]. After 10 years, Barthel et al. [2000] showed a survival rate of $13 \%$. We can observe a decreasing survival rate over time for this treatment, ending up with a very poor prognosis for tooth vitality in longer periods.

Stepwise Excavation. In order to avoid pulp exposure and consequently increase tooth vitality, SW is suggested. In a randomized clinical trial Bjørndal et al. [2010] showed a survival rate of $74 \%$ after 1 year of follow-up compared with $62.4 \%$ after SRFD.

Selective Removal to Soft Dentin. There are very few studies of SRSD with long follow-up periods. Quantitative and qualitative radiographic assessment over a 10year period of SRSD showed an increased radiopacity of the carious dentin left in the cavity floor, showing mineral deposition [Alves et al., 2010]. The survival rate of the therapy was $90 \%$ after 3 years, $82 \%$ after 5 years, and $63 \%$ at 10 years of follow-up. When the failures caused by fracture were disregarded, success rates increased to 93 and $80 \%$ at the 5 - and 10 -year recalls [Maltz et al., 2011]. Franzon et al. [2007], studying deciduous teeth, showed a survival rate of $79 \%$ after 3 years and $88 \%$ after 5 years [Franzon et al., 2009].

SRSD in deep caries lesion was compared with SW in an RCT [Maltz et al., 2012a, 2013]. The results showed that there was no association between pulp necrosis and gender, age, and filling material (amalgam or resin) after 5 years. Only an association between pulp necrosis and the treatment (SW or SRSD) was observed. The pulp vitality survival rate after 3 years was $78 \%$ for SRSD compared with 53\% for SW treatment (fig. 5a). The higher number of incomplete SW treatments (only the first step of the treatment was performed) may explain this difference between treatments. The comparison of survival rates between teeth that had completed $(\mathrm{n}=114)$ and incomplete SW $(\mathrm{n}=26)$ indicated 88 and $5 \%$ after 5 years of follow-up (fig. 5b). Completed SW presented survival rates similar to those of SRSD [unpubl. data]. Schwendicke et al. [2013] performed a systematic review to assess the failure of incomplete dentin caries removal (SRSD and SW) and to evaluate whether incompletely excavated teeth fail due to pulpal or non-pulpal complications. After incomplete removal of deep caries, pulpal failure was more common than non-pulpal failure. SRSD compared with SW reduces the risk of failure $(\mathrm{OR}=0.21,95 \% \mathrm{CI}$ : $0.08-0.55)$. Growing evidence indicates that SRSD seems to be the most appropriate treatment option for deep caries lesions.

The report of the International Caries Consensus Collaboration (ICCC) meeting [Schwendicke et al., 2016] states that 'carious tissue is removed purely to create conditions for long-lasting restorations. Bacterially contaminated or demineralized tissues close to the pulp do not need to be removed'. One important guiding principle during carious tissue removal in deep caries lesions is to maintain pulpal health by preventing pulp exposure (leave soft dentin in proximity to the pulp if required). However, in order to achieve a good sealing and a longlasting restoration, NSRHD on the surrounding cavity walls is recommended.

Recently, a question was raised about the relation between NSRHD/SRFD and SRSD and restorations longevity. Hevinga et al. [2010] found in an in vitro study that restored teeth after incomplete excavation have lower fracture strengths than restored teeth after NSRHD. Schwendicke et al. [2014], on the other hand, in an in vitro study found that fracture resistance was not significantly different between teeth with or without remaining demineralized dentin. It is important to be aware that carious dentin that is adequately sealed will remineralize, resulting in great hardness and stiffness [Alves et al., 2010; Franzon et al., 2009] and probably higher fracture strength over time. It does not seem that the remaining carious tissue plays an important role in restoration longevity, as can be observed comparing studies of restorations placed over firm/hard or soft dentin. We can observe 70-92\% success rates after a 5-year follow-up [Köhler et al., 2000; Opdam et al., 2004] and 50-79\% success rates after a 10year follow-up of restorations placed on firm/hard dentin [Gaengler et al., 2001; Lundin and Koch, 1999], with mean annual failure rates for posterior direct restorations varying between 1 and 3\% [Heintze and Rousson, 2012; Opdam et al., 2014]. Recently, Maltz et al. [2016, unpubl. data] performed a study comparing survival rates of restorations placed in deep caries lesions with or without decayed tissue beneath them over a 5-year period. This study used data collected in a previous multicenter randomized controlled clinical trial (Clinical Trial Registration NCT00887952) [Maltz et al., 2012a, 2013]. The survival analysis showed similar success rates for SW (76\%) 


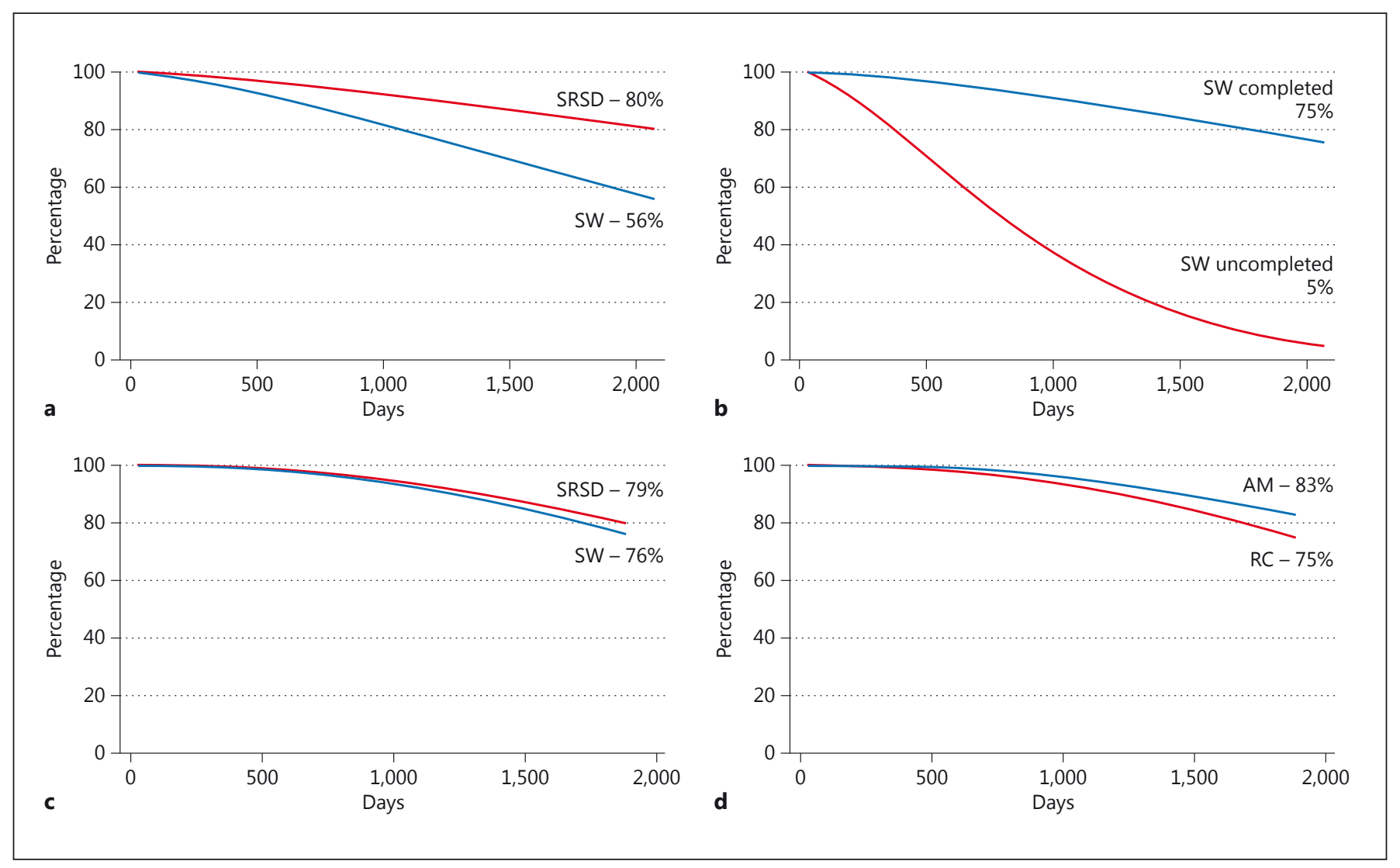

Fig. 5. Cumulative survival rates of SRSD and SW treatments (a) and completed and uncompleted SW (b) considering pulp vitality outcome at the 5-year follow-up. Cumulative survival rates of SRSD and SW treatments (c) and the filling materials amalgam and resin composite (d) considering restorative treatment longev- ity at the 5-year follow-up. AM = Amalgam; $\mathrm{RC}=$ resin composite; SW completed $=$ the two steps of the treatment were performed; SW uncompleted = only the first step of the treatment was performed. and SRSD (79\%) (fig. 5c) and for amalgam and resin composite (fig. $5 \mathrm{~d}$ ). The vast majority of the failures were caused by restoration fracture. The most frequent reasons for failures reported in clinical studies are fracture of the restoration and secondary caries [Opdam et al., 2004; Sunnegårdh-Grönberg et al., 2009]. So far, the presence of decayed tissue beneath restorations in deep caries lesions does not seem to affect the survival of the restorations. SRSD seems not to affect restoration longevity.

\section{Conclusions and Recommendations}

Based on the evidence presented and discussed in the above sections the following conclusions and recommendations may be made concerning the biological approach for the diagnosis and management of occlusal caries lesions:
1 Only few studies using molecular methods focus on biofilms in relation to occlusal caries. Future studies should explore the relationship between the function and the structural composition of these biofilms to understand the role of occlusal biofilms in caries development.

2 State-of-the-art measures to evaluate the risk for occlusal caries lesion activity, incidence, and progression should include the assessment of the visible occlusal biofilm and the stage of tooth eruption. Thus, further research should focus on the management of the occlusal biofilm and its consequences for caries activity and tooth survival.

3 When the non-cavitated caries lesions are of concern, careful clinical examination, including assessment of the lesion activity status, remains the major tool to determine the immediate treatment need as well as to follow up on the non-operative treatment outcome. 
4 Even medium occlusal caries lesions in the permanent dentition may be treated by non-invasive fissure sealing. By extending the criteria to include small and medium occlusal caries lesions for non-invasive treatments, traditional restoration of occlusal surfaces can be postponed or even avoided, and the dental health of children and adolescents can be improved.

5 SRSD is recommended in deep carious lesions. SRFD has a lower success rate due to increased pulp exposure in the presence of infected dentin. SRSD has greater success rates compared with SW.

\section{Author Contributions}

J.C.C. wrote the Introduction, Risk Assessment for Occlusal Caries Lesion Activity, Incidence and Progression, and consolidated the full text. I.D. wrote Molecular Ecology of Biofilms on Occlusal Surfaces. V.M. wrote Challenges in Diagnosing and Managing Non-Cavitated Occlusal Lesions. V.Q. and A.B. wrote Management of Small and Medium Occlusal Caries Lesions. M.M. and C.F.-P. wrote Management of Deep Occlusal Caries Lesions. All authors wrote their conclusions.

\section{Disclosure Statement}

The authors have no conflicts of interest to declare.

\section{References}

Aas JA, Griffen AL, Dardis SR, Lee AM, Olsen I, Dewhirst FE, Leys EJ, Paster BJ: Bacteria of dental caries in primary and permanent teeth in children and young adults. J Clin Microbiol 2008;46:1407-1417.

Aas JA, Paster BJ, Stokes LN, Olsen I, Dewhirst FE: Defining the normal bacterial flora of the oral cavity. J Clin Microbiol 2005;43:57215732.

Addy M, Renton-Harper P, Myatt GA: A plaque index for occlusal surfaces and fissures. Measurement of repeatability and plaque removal. J Clin Periodontol 1988;25:164-168.

Ahovuo-Saloranta A, Forss H, Walsh T, Hiiri A, Nordblad A, Makela M, Worthington HV: Sealants for preventing dental decay in the permanent teeth. Cochrane Database Syst Rev 2013;3:CD001830.

Al-Ahmad A, Follo M, Selzer AC, Hellwig E, Hannig M, Hannig C: Bacterial colonization of enamel in situ investigated using fluorescence in situ hybridization. J Med Microbiol 2009;58:1359-1366.

Al-Khatrash AA, Badran YM, Alomari QD: Factors affecting the detection and treatment of occlusal caries using the International Caries Detection and Assessment System. Oper Dent 2011;36:597-607.

Alves L, Fontanella V, Damo A, Ferreira de Oliveira E, Maltz M: Qualitative and quantitative radiographic assessment of sealed carious dentin: a 10-year prospective study. Oral Surg Oral Med Oral Pathol Oral Radiol Endod 2010;109:135-141.

Amann RI, Binder BJ, Olson RJ, Chisholm SW, Devereux R, Stahl DA: Combination of $16 \mathrm{~S}$ rRNA-targeted oligonucleotide probes with flow cytometry for analyzing mixed microbial populations. Appl Environ Microbiol 1990; 56:1919-1925.

Arif N, Sheehy EC, Do T, Beighton D: Diversity of Veillonella spp. from sound and carious sites in children. J Dent Res 2008;87:278-282.
Baelum V, Hintze H, Wenzel A, Danielsen B, Nyvad B: Implications of caries diagnostic strategies for clinical management decisions. Community Dent Oral Epidemiol 2012;40: 257-266.

Baelum V, Machiulskiene V, Nyvad B, Richards A, Vaeth M: Application of survival analysis to carious lesion transitions in intervention trials. Community Dent Oral Epidemiol 2003; 31;252-260.

Bakhshandeh A, Qvist V, Ekstrand KR: Sealing occlusal caries lesions in adults referred for restorative treatment: 2-3 years of follow-up. Clin Oral Investig 2012;16:521-529.

Banerjee A, Yasseri M, Munson M: A method for the detection and quantification of bacteria in human carious dentine using fluorescent in situ hybridisation. J Dent 2002;30:359-363.

Barthel CR, Rosenkranz B, Leuenberg A, Roulet JF: Pulp capping of carious exposures: treatment outcome after 5 and 10 years: a retrospective study. J Endod 2000;26:525-528.

Batchelor PA, Sheiham A: grouping of tooth surfaces by susceptibility to caries: a study in 5-16 year-old children. BMC Oral Health 2004;4:2.

Beauchamp J, Caufield PW, Crall JJ, Donly K, Feigal R, Gooch B, Ismail A, Kohn W, Siegal M, Simonsen R: Evidence-based clinical recommendations for the use of pit-and-fissure sealants: a report of the American Dental Association Council on Scientific Affairs. J Am Dent Assoc 2008;139:257-268.

Beck JD: Risk revisited. Community Dent Oral Epidemiol 1998;26:220-225.

Bernabé E, Sheiham A: Extent of differences in dental caries in permanent teeth between childhood and adulthood in 26 countries. Int Dent J 2014;64:241-245.
Bertella N, Moura dos S, Alves LS, Damé-Teixeira N, Fontanella V, Maltz M: Clinical and radiographic diagnosis of underlying dark shadow from dentin (ICDAS 4) in permanent molars. Caries Res 2013;47:429-432.

Bjørndal L, Larsen T, Thylstrup A: A clinical and microbiological study of deep carious lesions during stepwise excavation using long treatment intervals. Caries Res 1997;31:411-417.

Bjørndal L, Reit C, Bruun G, Markvart M, Kjaeldgaard M, Näsman P, Thordrup M, Dige I, Nyvad B, Fransson H, Lager A, Ericson D, Petersson K, Olsson J, Santimano EM, Wennström A, Winkel P, Gluud C: Treatment of deep caries lesions in adults: randomized clinical trials comparing stepwise vs. direct complete excavation, and direct pulp capping vs. partial pulpotomy. Eur J Oral Sci 2010;118:290-297.

Carvalho JC: Caries process on occlusal surfaces: evolving evidence and understanding. Caries Res 2014;48:339-346.

Carvalho JC, Ekstrand KR, Thylstrup A: Dental plaque and caries on occlusal surfaces of first permanent molars in relation to stage of eruption. J Dent Res 1989;68:773-779.

Carvalho JC, Ekstrand KR, Thylstrup A: Results after 1 year of non-operative occlusal caries treatment of erupting permanent first molars. Community Dent Oral Epidemiol 1991;19: 23-28.

Carvalho JC, Figueredo CS, Mestrinho HD: Clinical report on plaque formation, distribution and maturation within the primary, mixed and permanent dentitions. Eur J Paediatr Dent 2009;10:193-199.

Carvalho JC, Mestrinho HD: Diagnosing noncavitated lesions in epidemiological studies: practical and scientific considerations. Braz Oral Res 2014;28:1-7.

Carvalho JC, Mestrinho HD, Stevens S, van Wijk AJ: Do oral health conditions adversely impact young adults? Caries Res 2015;49:266-274. 
Carvalho JC, Thylstrup A, Ekstrand KR: Results after 3 years of non-operative occlusal caries treatment of erupting permanent first molars. Community Dent Oral Epidemiol 1992;20: 187-192.

Carvalho JC, Van Nieuwenhuysen JP, D'Hoore $\mathrm{W}$ : The decline in dental caries among Belgian children between 1983 and 1998. Community Dent Oral Epidemiol 2001;29:55-61.

Casagrande L, Bento LW, Dalpian DM, GarcíaGodoy F, de Araujo FB: Indirect pulp treatment in primary teeth: 4-year results. Am J Dent 2010;23:34-38.

Corralo DJ, Maltz M: Clinical and ultrastructural effects of different liners/restorative materials on deep carious dentin: a randomized clinical trial. Caries Res 2013;47:243-250.

Dewhirst FE, Chen T, Izard J, Paster BJ, Tanner AC, Yu WH, Lakshmanan A, Wade WG: The human oral microbiome. J Bacteriol 2010; 192:5002-5017.

Dige I, Gronkjaer L, Nyvad B: Molecular studies of the structural ecology of natural occlusal caries. Caries Res 2014;48:451-460.

Dige I, Raarup MK, Nyengaard JR, Kilian M, Nyvad B: Actinomyces naeslundii in initial dental biofilm formation. Microbiology 2009; 155:2116-2126.

Divaris K: Predicting Dental Caries outcomes in children: a 'risky' concept. J Dent Res 2016;95: 248-254.

Edwardsson S: Bacteriological studies on deep areas of carious dentine. Odontol Revy Suppl 1974;32:1-143.

Ekstrand KR, Bjørndal L: Structural analyses of plaque and caries in relation to the morphology of the groove-fossa system on erupting mandibular third molars. Caries Res 1997;31: 336-348.

Ekstrand KR, Kuzminaa IN, Kuzmina E, Christiansen ME: Two and a half-year outcome of caries-preventive programs offered to groups of children in the Solntsevsky District of Moscow. Caries Res 2000;34:8-19.

Espelid I, Tveit AB, Mejare I, Sundberg H, Hallonsten AL: Restorative treatment decisions on occlusal caries in Scandinavia. Acta Odontol Scand 2001;59:21-27.

Farzão P: Effectiveness of the bucco-lingual technique within a school-based supervised toothbrushing program on preventing caries: a randomized controlled trial. BMC Oral Health 2011;11:11.

Fellows JL, Gordan VV, Gilbert GH, Rindal DB, Qvist V, Litaker MS, Benjamin P, Flink H, Pihlstrom DJ, Johnson N: Dentist and practice characteristics associated with restorative treatment of enamel caries in permanent teeth: multiple-regression modeling of observational clinical data from the National Dental PBRN. Am J Dent 2014;27:91-99.

Fereira-Zandona A, Santjago E, Eckert GJ, Katz BP, Pereira de Oliveira S, Capin OR, Mau M, Zero DT: The natural history of dental caries: a 4-year observational study. J Dent Res 2012; 91:841-846
Fontana M, Santiago E, Eckert GJ, Ferreira-Zandona AG: Risk factors of caries progression in a Hispanic school-aged population. J Dent Res 2011;90:1189-1196.

Franzon R, Casagrande L, Pinto AS, García-Godoy F, Maltz M, de Araujo FB: Clinical and radiographic evaluation of indirect pulp treatment in primary molars: 36 months followup. Am J Dent 2007;20:189-192.

Franzon R, Gomes M, Pitoni CM, Bergmann CP, Araujo FB: Dentin rehardening after indirect pulp treatment in primary teeth. J Dent Child (Chic) 2009;76:223-228.

Fyffe HE, Deery C, Nugent ZJ, Nuttall NM, Pitts NB: Effect of diagnostic threshold on the validity and reliability of epidemiological caries diagnosis using the Dundee Selectable Threshold Method for caries diagnosis. Community Dent Oral Epidemiol 2000;28:42-51.

Gaengler P, Hoyer I, Montag R: Clinical evaluation of posterior composite restorations: the 10-year report. J Adhes Dent 2001;3:185-194.

Galil KA, Gwinnett AJ: Human tooth-fissure contents and their progressive mineralization. Arch Oral Biol 1975;20:559-562.

Gimenez T, Braga MM, Raggio DP, Deery C, Ricketts DN, Mendes FM: Fluorescencebased methods for detecting caries lesions: systematic review, meta-analysis and sources of heterogeneity. PLoS One 2013;8:e60421.

Gordan VV, Bader JD, Garvan CW, et al: Restorative treatment thresholds for occlusal primary caries among dentists in the dental practice-based research network. J Am Dent Assoc 2010;141:171-184.

Gore DR: The use of dental sealants in adults: a long-neglected preventive measure. Int J Dent Hyg 2010;8:198-203.

Griffin SO, Oong E, Kohn W, Vidakovic B, Gooch BF, Bader J, Clarkson J, Fontana MR, Meyer DM, Rozier RG, Weintraub JA, Zero DT: The effectiveness of sealants in managing caries lesions. J Dent Res 2008;87:169-174.

Handelman SL, Washburn F, Wopperer P: Twoyear report of sealant effect on bacteria in dental caries. J Am Dent Assoc 1976;93:967-970.

Heintze SD, Rousson V: Clinical effectiveness of direct class II restorations - a meta-analysis. J Adhes Dent 2012;14:407-431.

Hevinga MA, Opdam NJ, Frencken JE, Truin GJ, Huysmans MC: Does incomplete caries removal reduce strength of restored teeth? J Dent Res 2010;89:1270-1275.

Hickel R, Manhart J: Longevity of restorations in posterior teeth and reasons for failure. J Adhes Dent 2001;3:45-64.

Hoshino E: Predominant obligate anaerobes in human carious dentin. J Dent Res 1985;64: 1195-1198.

Ismail AI: Visual and tactile detection of dental caries. J Dent Res 2004;83:C56-C66.

Jensen OE, Handelman SL: Effect of an autopolymerizing sealant on viability of microflora in occlusal dental caries. Scand J Dent Res 1980; 88:382-388.
Jiang W, Jiang Y, Li C, Liang J: Investigation of supragingival plaque microbiota in different caries status of Chinese preschool children by denaturing gradient gel electrophoresis. $\mathrm{Mi}$ crob Ecol 2011;61:342-352.

Keijser BJ, Zaura E, Huse SM, van der Vossen JM, Schuren FH, Montijn RC, ten Cate JM, Crielaard W: Pyrosequencing analysis of the oral microflora of healthy adults. J Dent Res 2008; 87:1016-1020.

Kervanto-Seppala S, Pietila I, Meurman JH, Kerosuo E: Pit and fissure sealants in dental public health - application criteria and general policy in Finland. BMC Oral Health 2009;9:5.

Köhler B, Rasmusson CG, Odman P: A five-year clinical evaluation of class II composite resin restorations. J Dent 2000;28:111-116.

Kongstad J, Ekstrand K, Qvist V, Christensen LB, Cortsen B, Gronbaek M, Holm-Pedersen P, Holmstrup P, Bardow A, Twetman S, Fiehn NE: Findings from the oral health study of the Danish Health Examination Survey 20072008. Acta Odontol Scand 2013;71:15601569.

Kopperud SE, Tveit AB, Opdam NJ, Espelid I: Occlusal caries management: preferences among dentists in Norway. Caries Res 2016;50:4047.

Kuzmina I, Ekstrand KR: Outcomes 18 years after implementation of a nonoperative caries preventive program - the Nexö method - on children in Moscow, Russia. Community Dent Oral Epidemiol 2015;43:308-316.

Lagerweij MD, van Loveren C: Declining caries trends: are we satisfied? Curr Oral Health Rep 2015;2:212-217.

Levinkind M, Owens J, Morea C, Addy M, Lang NP, Adair R, Barton I: The development and validation of an occlusal site-specific plaque index to evaluate the effects of cleaning by tooth brushes and chewing gum. J Clin Periodontol 1999;26:177-182.

Li Y, Ge Y, Saxena D, Caufield PW: Genetic profiling of the oral microbiota associated with severe early-childhood caries. J Clin Microbiol 2007;45:81-87.

Lima KC, Coelho LT, Pinheiro IV, Rocas IN, Siqueira JF Jr: Microbiota of dentinal caries as assessed by reverse-capture checkerboard analysis. Caries Res 2011;45:21-30.

Löe H, Karring T, Theilade E: An in vivo method for the study of the microbiology of occlusal fissures. Caries Res 1973;7:120-129.

Loesche WJ, Eklund S, Earnest R, Burt B: Longitudinal investigation of bacteriology of human fissure decay: epidemiological studies in molars shortly after eruption. Infect Immun 1984;46:765-772.

Lundin SA, Koch G: Class I and II posterior composite resin restorations after 5 and 10 years. Swed Dent J 1999;23:165-171.

MacGregor A, Marsland EA, Batty I: Experimental studies of dental caries. I. The relation of bacterial invasion to softening of the dentin. Br Dent J 1956;101:230-235. 
Machiulskiene V: Impact of different caries diagnostic methods on the measurements of caries prevalence and severity in children; doctoral thesis, Kaunas, KMU, 1999.

Machiulskiene V, Nyvad B, Baelum V: A comparison of clinical and radiographic caries diagnoses in posterior teeth of 12-year-old Lithuanian children. Caries Res 1999;33:340-348.

Machiulskiene V, Verroneau J, Tikhonova S, Pustavoitava N, Baelum V, Nyvad B: Calibration study of the Nyvad criteria for scoring caries lesion activity in the Cree community, Canada. Caries Res 2009;43:213.

Magnusson BO, Sundell SO: Stepwise excavation of deep carious lesions in primary molars. J Int Assoc Dent Child 1977;8:36-40.

Maltz M, Alves LS, Jardim JJ, Moura MoS, de Oliveira EF: Incomplete caries removal in deep lesions: a 10-year prospective study. Am J Dent 2011;24:211-214.

Maltz M, Barbachan e Silva B, Carvalho DQ, Volkweis A: Results after two years of nonoperative treatment of occlusal surface in children with high caries prevalence: Braz Dent J 2003;14:48-54.

Maltz M, de Oliveira EF, Fontanella V, Bianchi R: A clinical, microbiologic, and radiographic study of deep caries lesions after incomplete caries removal. Quintessence Int 2002;33: 151-159.

Maltz M, Garcia R, Jardim JJ, de Paula LM, Yamaguti PM, Moura MS, Garcia F, Nascimento C, Oliveira A, Mestrinho HD: Randomized trial of partial vs. stepwise caries removal: 3-year follow-up. J Dent Res 2012a;91:1026-1031.

Maltz M, Henz SL, de Oliveira EF, Jardim JJ: Conventional caries removal and sealed caries in permanent teeth: a microbiological evaluation. J Dent 2012b;40:776-782.

Maltz M, Jardim JJ, Mestrinho HD, Yamaguti PM, Podestá K, Moura MS, de Paula LM: Partial removal of carious dentine: a multicenter randomized controlled trial and 18-month follow-up results. Caries Res 2013;47:103109.

Mantzourani M, Gilbert SC, Sulong HN, Sheehy EC, Tank S, Fenlon M, Beighton D: The isolation of bifidobacteria from occlusal carious lesions in children and adults. Caries Res 2009; 43:308-313.

Marsh PD: Microbial ecology of dental plaque and its significance in health and disease. Adv Dent Res 1994;8:263-271.

Marthaler TM: Changes in dental caries 19532003. Caries Res 2004;38:173-81.

Matsuo T, Nakanishi T, Shimizu H, Ebisu S: A clinical study of direct pulp capping applied to carious-exposed pulps. J Endod 1996;22: 551-556.

Meiers JC, Schachtele CF: Fissure removal and needle scraping for evaluation of the bacteria in occlusal fissures of human teeth. J Dent Res 1984;63:1051-1055.

Mejàre I, Axelsson S, Dahlén G, Espelid I, Norlund A, Tranæus S, Twetman S: Caries risk assessment. A systematic review. Acta Odontol Scand 2014;72:81-91
Mejàre I, Stenlund H, Zelezny-Holmlund C: Caries incidence and lesion progression from adolescence to young adulthood: a prospective 15 -year cohort study in Sweden. Caries Res 2004;38:130-141.

Mertz-Fairhurst EJ, Curtis JW Jr, Ergle JW, Rueggeberg FA, Adair SM: Ultraconservative and cariostatic sealed restorations: results at year 10. J Am Dent Assoc 1998;129:55-66.

Munson MA, Banerjee A, Watson TF, Wade WG: Molecular analysis of the microflora associated with dental caries. J Clin Microbiol 2004; 42:3023-3029.

Nørrisgaard PE, Qvist V, Ekstrand K: Prevalence, risk surfaces and inter-municipality variations in caries experience in Danish children and adolescents in 2012. Acta Odontol Scand 2016;74:291-297.

Nourallah AW, Splieth CH: Efficacy of occlusal plaque removal in erupting molars: a comparison of an electric toothbrush and the crosstoothbrushing technique. Caries Res 2004;38: 91-94.

Nyvad B, Crielaard W, Mira A, Takahashi N, Beighton D: Dental caries from a molecular microbiological perspective. Caries Res 2013; 47:89-102.

Nyvad B, Fejerskov O: Assessing the stage of caries lesion activity on the basis of clinical and microbiological examination. Community Dent Oral Epidemiol 1997;25:69-75.

Nyvad B, Machiulskiene V, Baelum V: Reliability of a new caries diagnostic system differentiating between active and inactive caries lesions. Caries Res 1999;33:252-260.

Nyvad B, Machiulskiene V, Baelum V: Construct and predictive validity of clinical caries diagnostic criteria assessing lesion activity. J Dent Res 2003;82:117-122.

Nyvad B, Machiulskiene V, Fejerskov O, Baelum V: Diagnosing dental caries in populations with different levels of dental fluorosis. Eur J Oral Sci 2009;117:161-168.

Oong EM, Griffin SO, Kohn WG, Gooch BF, Caufield PW: The effect of dental sealants on bacteria levels in caries lesions: a review of the evidence. J Am Dent Assoc 2008;139:271-278

Opdam NJ, Loomans BA, Roeters FJ, Bronkhorst EM: Five-year clinical performance of posterior resin composite restorations placed by dental students. J Dent 2004;32:379-383.

Opdam NJ, van de Sande FH, Bronkhorst E, Cenci MS, Bottenberg P, Pallesen U, Gaengler P, Lindberg A, Huysmans MC, van Dijken JW: Longevity of posterior composite restorations: a systematic review and meta-analysis. J Dent Res 2014;93:943-949.

Pereira AC, Eggertsson H, Martinez-Mier EA, Mialhe FL, Eckert GJ, Zero DT: Validity of caries detection on occlusal surfaces and treatment decisions based on results from multiple caries-detection methods. Eur J Oral Sci 2009;117:51-57.

Peterson SN, Snesrud E, Liu J, Ong AC, Kilian M, Schork NJ, Bretz W: The dental plaque microbiome in health and disease. PLoS One 2013; 8:e58487.
Pinto AS, de Araújo FB, Franzon R, Figueiredo MC, Henz S, García-Godoy F, Maltz M: Clinical and microbiological effect of calcium hydroxide protection in indirect pulp capping in primary teeth. Am J Dent 2006;19:382-386.

Poulsen S, Laurberg L, Vaeth M, Jensen U, Haubek D: A field trial of resin-based and glass-ionomer fissure sealants: clinical and radiographic assessment of caries. Community Dent Oral Epidemiol 2006;34:36-40.

Qvist V: Longevity of restorations: 'the death spiral'; in Fejerskov O, Nyvad B, Kidd E (eds): Dental Caries: The Disease and Its Clinical Management. Hoboken, Wiley-Blackwell, 2015, pp 387-401.

Razmiene J: Caries prevalence and severity in Lithuanian 4-6 year-old children attending kindergartens; doctoral thesis, Kaunas, LSMU, 2013.

Schwendicke F, Frencken JE, Bjørndal L, Maltz M, Manton DJ, Ricketts D, Van Landuyt K, Banerjee A, Campus G, Doméjean S, Fontana M, Leal S, Lo E, Machiulskiene V, Schulte A, Splieth C, Zandona AF, Innes NP: Managing carious lesions: consensus recommendations on carious tissue removal. Adv Dent Res 2016; 28:58-67.

Schwendicke F, Göstemeyer G, Gluud C: Cavity lining after excavating caries lesions: metaanalysis and trial sequential analysis of randomized clinical trials. J Dent 2015a;43:12911297.

Schwendicke F, Jager AM, Paris S, Hsu LY, Tu YK: Treating pit-and-fissure caries: a systematic review and network meta-analysis. J Dent Res 2015b;94:522-533.

Schwendicke F, Kern M, Meyer-Lueckel H, Boels A, Doerfer C, Paris S: Fracture resistance and cuspal deflection of incompletely excavated teeth. J Dent 2014;42:107-113.

Schwendicke F, Meyer-Lueckel H, Dörfer C, Paris S: Failure of incompletely excavated teeth - a systematic review. J Dent 2013;41: 569-580.

Senneby A, Mejàre I, Sahlin NE, Svensäter G, Rohlin M: Diagnostic accuracy of different caries risk assessment methods. A systematic review. J Dent 2015;43:1385-1393.

Shovelton DS: A study of deep carious dentine. Int Dent J 1968;18:392-405.

Simonsen RJ: Pit and fissure sealant: review of the literature. Pediatr Dent 2002;24:393-414.

Simón-Soro A, Tomas I, Cabrera-Rubio R, Catalan MD, Nyvad B, Mira A: Microbial geography of the oral cavity. J Dent Res 2013;92:616621

Sunnegårdh-Grönberg K, van Dijken JW, Funegård $\mathrm{U}$, Lindberg $\mathrm{A}$, Nilsson $\mathrm{M}$ : Selection of dental materials and longevity of replaced restorations in public dental health clinics in northern Sweden. J Dent 2009;37:673-678.

Takahashi N: Oral microbiome metabolism: from 'who are they?' to 'what are they doing?'. J Dent Res 2015;94:1628-1637.

Takahashi N, Nyvad B: Caries ecology revisited: microbial dynamics and the caries process. Caries Res 2008;42:409-418. 
Tellez M, Gomez J, Pretty I, Ellwood R, Ismail AI: Evidence on existing caries risk assessment systems: are they predictive of future caries? Community Dent Oral Epidemiol 2013;41: 67-78.

Theilade J, Fejerskov O, Hørsted M: A transmission electron microscopic study of 7-day old bacterial plaque in human tooth fissures. Arch Oral Biol 1976;21:587-598.

Topping GV, Pitts NB; International Caries Detection and Assessment System Committee: Clinical visual caries detection. Monogr Oral Sci 2009;21:15-41.

Thylstrup A, Bruun C, Holmen L: In vivo caries models - mechanisms for caries initiation and arrestment. Adv Dent Res 1994;8:144-157.

Thylstrup A, Fejerskov O: Clinical and pathological features of dental caries; in Thylstrup A, Fejerskov O (eds): Textbook of Clinical Cariology, ed 2. Copenhagen, Munksgaard, 1994, pp 111-148.
Thylstrup A, Qvist V: Principal enamel and dentine reactions during caries progressions; in Thylstrup A, Leach SA, Qvist V (eds): Dentine and Dentine Reactions in the Oral Cavity. Oxford, IRL Press, 1987, pp 3-16.

Twetman S, Fontana M: Patient caries risk assessment. Monogr Oral Sci 2009;21:91-101.

Twetman S, Fontana M, Featherstone JD: Risk assessment - can we achieve consensus? Community Dent Oral Epidemiol 2013;41:e64e70.

Van Nieuwenhuysen JP, Carvalho JC, D'Hoore $\mathrm{W}$ : Caries reduction in Belgian 12-year-old children related to socioeconomic status. Acta Odontol Scand 2002;60:123-128.

Van Nieuwenhuysen JP, D'Hoore W, Carvalho JC: Caries experience among dental students in Belgium over 15 years. Caries Res 2004;38: 395.
Vermaire JH, Poorterman JH, van Herwijnen L, van Loveren C: A three-year randomized controlled trial in 6-year-old children on cariespreventive strategies in a general dental practice in the Netherlands. Caries Res 2014;48: 524-533.

Weber CM, Alves LS, Maltz M: Treatment decisions for deep carious lesions in the public health service in southern Brazil. J Public Health Dent 2011;71:265-270.

Welbury R, Raadal M, Lygidakis NA: EAPD guidelines for the use of pit and fissure sealants. Eur J Paediatr Dent 2004;5:179-184.

WHO: Country/Area Project Profile Database. WHO Collaborating Centre for Education, Training and Research in Oral Health, Malmö University. http://www.mah.se/capp/ (accessed December 2015).

Zijnge V, van Leeuwen MB, Degener JE, Abbas F, Thurnheer T, Gmür R, Harmsen HJ: Oral biofilm architecture on natural teeth. PLoS One 2010;5:e9321. 